\title{
Percursos Visuais no Acervo do MAC/USP: Uma Fenomenologia da Educação Artística
} Cauê Alves (Bolsista FAPESP - MAC/USP e DF/USP/SP) Orientadora: Carmen Aranha

Percursos visuais no acervo do MAC/USP: uma fenomenologia da educação artística, tem como proposta geral uma reflexão sobre a apreensão da obra de arte, através de estudo de determinados referenciais da Fenomenologia da Percepção desenvolvidos por Maurice Merleau-Ponty, e elaboração de materiais visuais de apoio para os professores de $1^{\circ}$ e $2^{\circ}$ graus das redes de ensino pública e particular, bem como do visitante em geral.

O projeto de Iniciação Científica vinculado a esta pesquisa se desenvolve através dos seguintes itens: 1) pesquisa biográfica de artistas selecionados e estudo sobre História da Arte Moderna e Contemporânea; 2) estudo de características formais da expressão visual e suas correlações para a elaboração da análise das obras selecionadas; 3 ) elaboração e aplicação de percursos em visitas orientadas ao acervo do Museu de Arte Contemporânea para grupos escolares; 4) apoio na elaboração e divulgação do material nas páginas do Museu na Internet.

O texto que se segue é uma primeira reflexão sobre alguns referenciais teóricos que embazam o projeto de Iniciação Científica.

\section{Fenomenologia do Visível: uma Primeira Leitura de Merleau-Ponty}

Fazer uma fenomenologia do visível, no caso em questão, é tentar uma descrição dos fenômenos estéticos que aparecem nas expressões das artes plásticas. Os fenômenos estéticos visíveis surgem em correlações, num entre-mundo, entre o percebido e quem o percebe. Perceber é uma forma de conhecimento que possui uma estrutura, é uma ordem de correlações.

Uma percepção, segundo Merleau-Ponty, sempre pode ser corrigida por outra. Ao contrário do que diria um cartesiano, que abandonaria todos os dados da percepção para que as idéias a corrigissem. Ela, neste caso, nos enganaria, nos iludiria. "Contudo seria mais límpido em nossa filosofia se se pudesse exorcizar esses espectros, fazer deles ilusões ou percepções sem objeto, à margem de um mundo sem equívoco! A Dióptrica de Descartes é essa tentativa. É o breviário de um pensamento que não mais quer assediar o visível e decide reconstrui-lo segundo o modelo que dele proporciona. (Para Descartes) o melhor é pensar a luz como uma ação por contato (...). O modelo de visão cartesiano é o tato."1

Em oposição aos empiristas, Merleau-Ponty coloca que a percepção não é obtida através da soma de sensações, pois nunca temos sensações parciais ou pontuais. O sujeito não conhece apenas associando sensações e impressões recebidas pelos órgãos dos sentidos. A sensação é um princípio para que a percepção possa tornar-se o solo do conhecimento fenomenológico. Uma obra de arte percebida não é um feixe de qualidades isoladas, nem somente uma idéia. Ela é um 
todo, percebida como uma estrutura. O fenômeno visível percebido pela consciência se oferece por perspectivas, por perfis; por isso, podemos sempre olhar um quadro e, cada vez, vê-lo de uma forma diferente e nova.

...o vidente não se apropria daquilo que vê: só se aproxima dele pelo olhar..."2

A consciência é como um sujeito que a princípio pode conhecer as coisas e pode criar, por exemplo, uma obra de arte e constituir as significações das coisas, dar sentidos à elas. A consciência está no mundo, habita um corpo, não poderia estar separada dele e ser puramente reflexiva. O corpo, por sua vez, não é somente um fato natural, um objeto de estudo das ciências, segundo relações de causa e efeito. Criticando essa posição naturalista, Merleau-Ponty inicia o Olho e o Espírito;

"A ciência manipula as coisas e renuncia a habitá-las. Fabrica para si modelos internos delas e, operando sobre esses índices ou variáveis as transformações permitidas por sua definição, só de longe em longe se defronta com o mundo atual. Ela é, e sempre foi, esse pensamento admiravelmente ativo, engenhoso, desenvolto, esse parti pris de tratar todo ser como 'objeto em geral' isto é, a um tempo como se ele nada fosse para nós, e, no entanto, se achasse predestinado aos nossos artifícios." ${ }^{3}$

De acordo com Husserl conhecer é um retorno às coisas mesmas, uma ida ao encontro das origens do conhecimento, da apreensão do fenômeno penetrado no logos, como a percepção. É um retorno ao mundo pré-científico, que precede o conhecimento racional. Por isso a tarefa da Fenomenologia é descrever e não analisar ou explicar os atos de consciência.

O corpo, que não é um feixe de funções, um fato natural, é visível, está no mundo visível e é também reflexivo, pode se tocar e ser tocado sem sabermos ao certo quem é o sujeito tocante e quem é o tocado. A consciência está num corpo visível, mas ela não é um fato observável, tão pouco uma entidade espiritual, uma alma. Ela é uma atividade que pode dar sentido às coisas, ou seja, ela sempre visa alguma coisa. A consciência é sempre de alguma coisa, se realiza por atos como o perceber e visa conteúdos, o percebido (correlato). A consciência é intencional e sem ela não existiria o mundo para nós; por outro lado, sem o mundo a consciência não teria a que dar significado.

Para a Fenomenologia não é válida a separação entre o mundo, as coisas e a minha consciência, o meu corpo. Ser um corpo é estar ligado ao mundo, nosso corpo não está no espaço, ele faz parte do espaço e a espacialidade do corpo é um desdobramento do seu ser. Não temos portanto a clássica separação entre sujeitoobjeto, o mundo está todo dentro de mim e eu estou todo fora. Um exemplo dessa idéia é dado por Merleau-Ponty: O desenho e o quadro "são o interior do exterior e o exterior do interior, que a duplicidade do sentir torna possíveis" ${ }^{\prime \prime}$ visível, por exemplo uma tela, um objeto que ocupa um lugar no mundo, se dá dentro do vidente que habita um corpo, também, imerso na visibilidade, gerando uma reversibilidade entre vidente e visível. O mundo desperta uma visibilidade dentro de mim, do meu corpo, que também faz parte do mundo, está fora, é visível. "O enigma reside nisso: meu corpo é ao mesmo tempo vidente e visível. Ele, que olha todas as coisas também pode olhar a si e reconhecer no que está vendo então o outro lado de seu poder vidente. (...) Elas (as coisas) são anexo, um prolongamento dele mesmo, estão encrustadas em sua carne, fazem parte de sua definição plena, e o 
mundo e feito do próprio estofo do corpo." ${ }^{\text {5 }}$

"O que constitui enigma é a sua ligação, é aquilo que está entre elas é que eu veja as coisas cada uma em seu lugar justamente porque elas se eclipsam umas às outras é que sejam rivais perante meu olhar precisamente por estarem cada uma em seu lugar. É a sua exterioridade conhecida no envolvimento delas e a mútua dependência delas na sua autonomia."

A partir da fusão entre consciência intencional que habita um corpo reflexivo e mundo, e do conceito de percepção se dá a Fenomenologia do visível. O fenômeno estético é apreendido após ser descrito em seus vários modos de ser visto, ou seja, não se tem em vista a interpretação estética da obra, ou mesmo históricosociológica, não se levanta qualquer crítica em relação a obra de arte, mas olha-se o dado imediato na sua multiplicidade de aparências para o conhecer visual, permitindo uma descrição daquilo que é visto e tentando tornar visível o fenômeno estético que surge nas correlações e intervalos. Ao torná-lo visível, nos aproximamos das essências que, embora não possam ser derivadas das aparências, podem ser intuídas através dos atos perceptivos. Para Merleau-Ponty não há distinção entre essência e aparência.

Para tornar visível a idéia do projeto vemos abaixo, como exemplo, uma parte do material visual Desenhos de Geraldo de Barros, com biografia e amálise das obras. A leitura da obra de arte, através de referenciais da Fenomenologia, se dá pela descrição das correlações dos elementos visíveis e invisíveis da expressão plástica como: cor, luz, materialidades, relações de volumes e profundidades, os ritmos da composição e suas movimentações. Em seguida uma breve descrição de como se dá a parte prática do projeto em visitas orientadas ao acervo do MAC. Esse e outros percursos podem ser vistos nas páginas do Museu na Internet pelo site: http://www.usp.br/mac

\section{Biografia de Geraldo de Barros}

Nasceu em Xavantes, no interior de São Paulo, em 1923. Iniciou seus estudos em pintura em 1945, tendo como professor Clóvis Graciano. No mesmo ano filiou-se ao sindicato dos artistas plásticos e à Associação Paulista de Belas Artes.

No ano seguinte foi aluno de Colette Pujol e, em 1947, de Yoshiya Takaoka com quem fundou o grupo XV. O grupo foi assim chamado porque eram 15 os integrantes, na maioria pintores japoneses. Com tendência expressionista realizavam pintura figurativa. Nessa época entrou em contato, através de livros, com a obra de Klee, Kandinsky, e com o desenho industrial da Bauhaus. Os desenhos que compõe o percurso datam dessa época.

Desde 1946 havia iniciado pesquisas em fotografia e gravura. No Foto-Cine Clube Bandeirantes deu continuidade a essas experimentações. Em 1949 organizou o laboratório fotográfico do MASP, onde pôde também preparar a exposição Fotoformas. Nesses trabalhos não se distingue a fotografia, da gravura e do desenho. Os negativos são sobrepostos, recortados, pintados com nanquim ou ponta seca e até perfurados, ampliando assim os limites do suporte. Por esses trabalhos Geraldo de Barros é um dos responsáveis pela fotografia moderna brasileira. Com ele a fotografia deixou de ser apenas uma forma de representação e tornou-se expressão artística.

Em 1951, recebeu bolsa de estudo do governo francês e transferiu-se para Paris. Lá 
frequentou a Escola de Belas Artes onde estudou Litografia e interessou-se por design gráfico. No atelier de Hayter estudou gravura. Teve contato com o pintor Giorgio Morandi, o fotógrafo Cartier-Bresson entre outros. Em Zurique conheceu Max Bill e seus textos teóricos sobre a função social do artista. Esse encontro foi importante para o rumo dos concretistas brasileiros.

Adotou uma postura baseada na teoria da Gestalt (psicologia da forma), onde o desenho não representa, ele torna visível. Os concretistas pintavam formas geometrizadas e simétricas formando um organismo fechado, compacto, um todo que é mais que as partes.

Com Waldemar Cordeiro e Sacilotto participou da fundação do Grupo Ruptura, em 1952 em São Paulo, principal grupo de arte concreta do Brasil. Neste mesmo ano trabalhou com artes gráficas e desenho industrial.

Em 1954 ao lado de Frei João Batista ligou-se a um grupo socialista e fundou a UNILABOR, uma cooperativa que fabricava móveis, mantinha uma escola de arte infantil, um grupo de teatro e um posto de saúde. Essa época se afastou um pouco da pintura. Em 1957 fundou o grupo FORMINFORM de desenho industrial e comunicação visual.

Em 1964 produziu o cartaz para o quarto centenário da cidade de São Paulo, ano que fundou a Hobjeto Industria de Móveis e design. Em 1966, ao lado de Nelson Leiner e Wesley Duke Lee, criou o Grupo Rex Time, responsáveis pelos primeiros happenings em São Paulo. Nessa época imerso na Pop Art e na Nova Figuração também realizou marcas, logotipos, cartazes e uma série de outdoors.

A partir do final da década de 70 retomou princípios concretos dos anos 50 , conceitos de serialização e cosumo em longa escala, usando a fórmica como suporte, visando sempre a socialização da arte. Geraldo de Barros faleceu em São Paulo em abril de 1998.

\section{Desenhos de Geraldo de Barros}

O Desenho tem uma especificidade dentro da expressão plástico visual: é uma forma de pensar o mundo, é uma estrutura de conhecimento que se dá através do exercício constante da apreensão visual de seus objetos. É do Desenho que se projetam as tensões visuais que estes objetos e suas correlações provocam.

Apreender o mundo através do Desenho é perceber a articulação intensa de linhas, formas, luzes, materiais, tramas, formações, luminosidades, materialidades e novos espaços.

Desenho é uma profundidade, é uma dimensão na qual mergulhamos e emergimos, diagramando visualmente nossas experiências. Como expressão plástica é também um registro, uma anotação gráfica, uma forma de tornar visível determinadas percepções, sínteses e estruturas gráficas.

"Os desenhos que produziu entre 1947 e 51 são intimistas por serem de pequenas proporções. Aqui Geraldo de Barros explora a magia do traço que corre sobre o papel, compondo figuras e cenas que formalizam experiências de luz e sombra, ritmo e criação de movimento. Naquele momento os desenhos provavelmente representaram para o artista exercícios de "aquecimento" Ainda assim, resultaram em pequenos poemas visuais." 


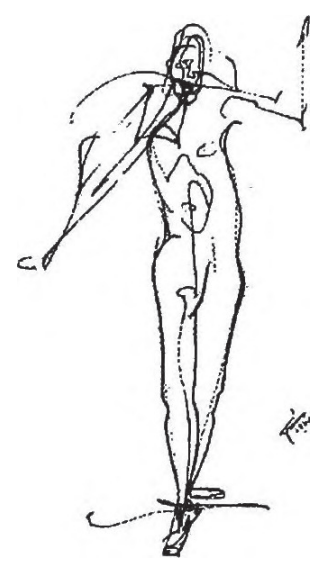

(Fig. 1; Sem Título, 1947)

O desenho de Geraldo de Barros mostra-se, em princípio, nos gestos rápidos de muitas movimentações, nas linhas de densidades e luzes diferentes que esboçam, também, a expressividade da figura.

O tema é desenvolvido através de um eixo central que se desenrola ao longo do tronco, marcando um ângulo nos pés da figura, cortado por uma linha horizontal, surgerindo a única profundidade deste desenho.

As diagonais que se desprendem do emaranhado de linhas na região do rosto, dando movimento aos braços, enfatizam tanto o equilíbrio vertical da figura, quanto criam sua instabilidade visual.

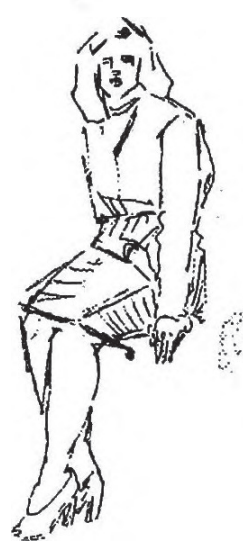

(Fig. 2; Sem Título, 1947)

Linhas orgânicas e contínuas desprendem-se do desenho anterior e agregamse à uma figura feminina em traços mais sintéticos, com toques mais curtos e ritmados; movimentações e variações de suas densidades e luzes modificam a natureza do desenho: a figura anterior sugere o início de um movimento; agora, temos o repouso.

O braço em apoio, o ângulo do quadril com as pernas situam a figura feminina 
neste estado e introduzem uma nova espacialidade: enquanto que a figura anterior mostra apenas uma profundidade, este desenho a envolve numa espacialidade total.

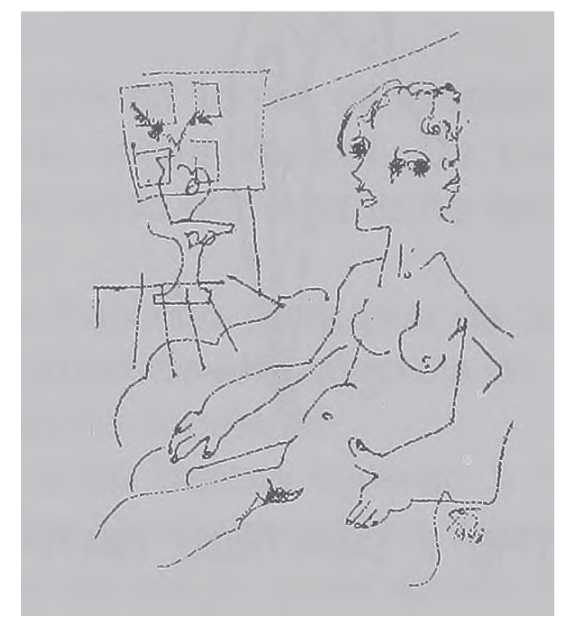

(Fig. 3; Sem Título, 1948)

O mesmo tema, a figura feminina, encontra aqui o mesmo repouso. Um modo de tratar as linhas, mais sintético ainda, novas descontinuidades, pontos que marcam pausas do nanquim sobre o papel, a falta de preocupação em delinear proporções; o braço direito, atrofiado, o braço esquerdo apoiado sobre a poltrona; o rosto de perfil, com três olhos, dois narizes e duas bocas; enfim, todos os elementos do desenho apresentam a figura dentro de uma sala e o espaço criado entorno da figura anterior vira um esquema: com linhas de fuga, o artista antecipa a figura para o primeiro plano. Profundidade renascentista revista. Entretanto, as linhas perdem densidades e luzes, ganham movimentos e variações sugerem novo estilo: traçados cubistas.

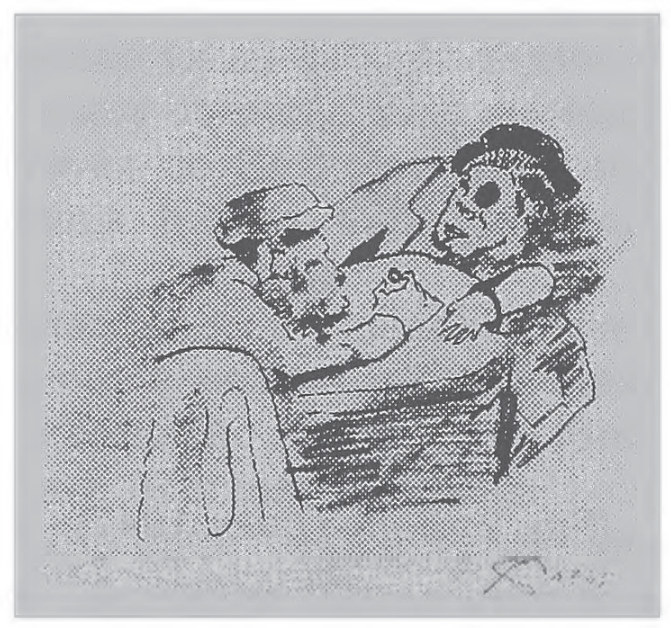

(Fig. 4; Sem Título, 1948)

As figuras se diluem no espaço que as circunda através da exploracão de novas materialidades: o nanquim desmancha-se no grafite. A construção da profundidade, que no desenho anterior era feita com pontos de vistas, volta a ser sugestão de espaço. Dos elementos anteriores encontramos muitos vestígios: linhas de densi- 
dades, luzes e movimentos diversos estão presentes; pontos que as interrompiam transformam-se em pequenas massas; suas continuidades e organicidades, também, transformam-se. Sobrepõe-se uma tensão nervosa nos traçados não vista anteriormente; linhas interrompem-se bruscamente, viram outros traçados viram massas, esfumaçam-se.

A profundidade do desenho muda: envoltas na nova luminosidade, definida por outras ligações, as figuras deflagram uma espacialidade que enfatiza uma diagonal e as movimenta levemente entorno de si próprias.

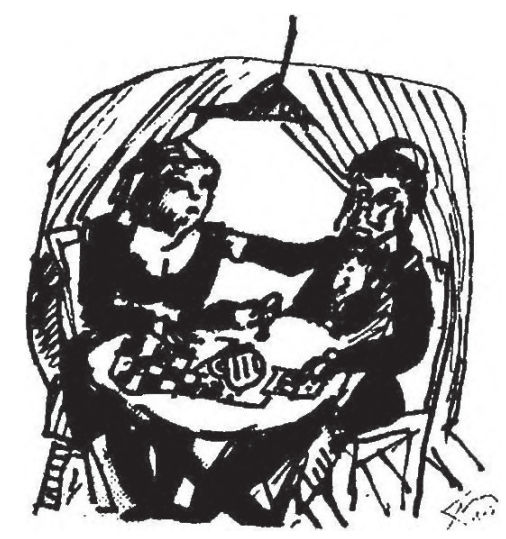

(Fig. 5; Sem Título, 1947)

Novamente duas pessoas sentadas à mesa. A cena nos remete ao desenho anterior. No entanto, observamos diferenças: os espaços criados neste desenho mostram-se aqui como uma síntese deste percurso visual: os vazios, a forma que emoldura as figuras, as luminosidades negras que as definem, as linhas densas, a elipse da mesa definem os primeiro, segundo e terceiro planos; ou seja, definem a profundidade do desenho sem, no entanto, repetir correlações já expressadas.

O nanquim, material deste desenho, opõe-se ao branco do suporte e, sem nenhuma gradação de cinzas, introduz a vibração dos dois tons.

Algumas expansões e geometrizações de formas contrastantes, como as deste desenho, sugerem a futura linguagem construtiva de Geraldo de Barros.

\section{Visitas Orientadas ao Acervo do MAC}

Procura-se sempre enfatizar a necessidade de nos livrarmos dos preconceitos e esclarecer a postura do educador-monitor. Não se tem em vista a explicação da obra de arte e sim um pensamento para provocar e despertar processos perceptivos, associações, comparações e relações. O monitor pode ajudar na contextualização histórica e biográfica dos artistas possibilitando também uma leitura da obra de arte, um diálogo, uma correlação entre o sujeito que percebe e o objeto percebido. Os visitantes sempre são estimulados a falarem sobre suas percepções das obras. Em geral, eles esperam que o monitor diga "a verdade" sobre a obra, como se isso existisse, e se considera um leigo em arte contemporânea que, muitas vezes, previamente acha tudo um lixo, colocando-se como alguém que não possui olhos para ver. A monitoria deve fazer com que o ele valorize seu olhar para assim poder 


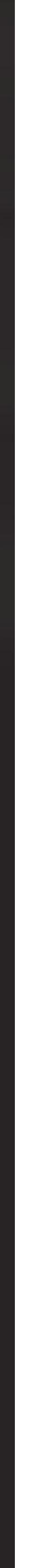

